\title{
Natural Clay Supported Zerovalent Iron Nanoparticles as a Potential Coagulant for Ammonia Reduction from Industrial Wastewater Effluents
}

\author{
Wighens I Ngoie* \\ Cape Peninsula University of Technology, South Africa
}

*Corresponding author: Wighens I Ngoie, Department of Chemical Engineering, Biocatalysis \& Technical Biology Research Group, Cape Peninsula University of Technology, Bellville Campus, South Africa.

Received Date: November 09, 2018

Published Date: June 10, 2019

\begin{abstract}
Currently in South Africa, many wastewater resources are polluted by anthropogenic sources, including household, agricultural waste and industrial processes. Though several conventional wastewater treatment techniques (among others, physical decantation, chemical oxidation, and disinfection) have been applied to remove contaminants, there are still some limitations, for the removal of chemicals such as ammonia [1,2]. It has been noticed that the level of ammonia of the effluents treated was comparatively higher [3] $(277 \mathrm{mg} / \mathrm{L})$ than what is required according to the South Africa National Standards [4] of Wastewater before being discharged into the environment (10mg/L). Public concern over the environmental impact of wastewater pollution has increased. To address this issue, experiments were carried out over a Jar Tester on sequential velocities (rapid mixing at $150 \mathrm{rpm}$ for $1 \mathrm{~min}$ and slow mixing at $20 \mathrm{rpm}$ for $20 \mathrm{~min}$ ) using activated clay (bentonite) in the attempt to remove ammonia from the wastewater effluent. The natural clay was activated with $5 \mathrm{M}$ sulphuric acid and amalgamated with Zerovalent Iron Nanoparticles (ZVINPs) in a mass ratio of 99:1. The physico chemically modified clay samples were characterized using X-ray fluorescence to have an idea about the mineralogical aspect of the coagulant before and after activation, and Brunner-Emmet-Teller (BET) method for surface area. The optimum dosage of coagulant to treat 1L of wastewater effluents was $61.6 \mathrm{mg}$ and the concentration of ammonia in the final product was about $8.71 \mathrm{mg} / \mathrm{L}$, approximately a reduction of $97 \%$. All parameters, such as $\mathrm{pH}$, conductivity complied with the Department of Water Affairs and Forestry.
\end{abstract}

Keywords: Activation; Clay; Zero valent iron nanoparticles; Ammonia; Wastewater effluents

\section{Introduction}

Water pollution is one of the largest environment problems in several countries. It mainly arises from wastewater released from household, industrial and agricultural processes. These effluents typically contain high concentrations of organic and inorganic chemicals such as hydrocarbon solvents, heavy metals, pesticides, dyes and so on. The toxicity, persistency and concentration of the contaminants result in serious environmental, public health and economic impacts [5]. Consequently, treatment of wastewater effluents before release into the environment is required. There are several wastewater treatment techniques including physical, chemical or biological processes i.e. coagulation, flocculation, adsorption, reverse osmosis, activated sludge and so on, which are used to remove pollutants from wastewater influents. Nevertheless, these conventional techniques have shown limitations, for the removal of ammonia. Use of activated clay, is one of the most promising techniques because the natural clay is of low-cost, is easy to obtain, and has good effectiveness and ability of degrading contaminants due to its adsorptive properties enhanced by sulphuric acid, which will supply charges to break the stability of ammonia in water by attracting them at the coagulant surface, then the activated clay will secondly be supported by zero valent iron nanoparticles in a homogenous mixture to increase the surface area on which the adsorption of pollutants will effectively take place $[6,7,8]$. Ion exchange and reverse osmosis have failed to destroy efficiently nitrate species and regenerate secondary brine wastes; electro-catalytic process necessitates higher potential to reduce nitrate into nitrogen. Basically, according to samples that were collected from several Wastewater plants in Cape Town, for instance, here below is the concentration trend of ammonia from the current WWTPs (red) comparatively to the standards (blue) (Figure 1). 


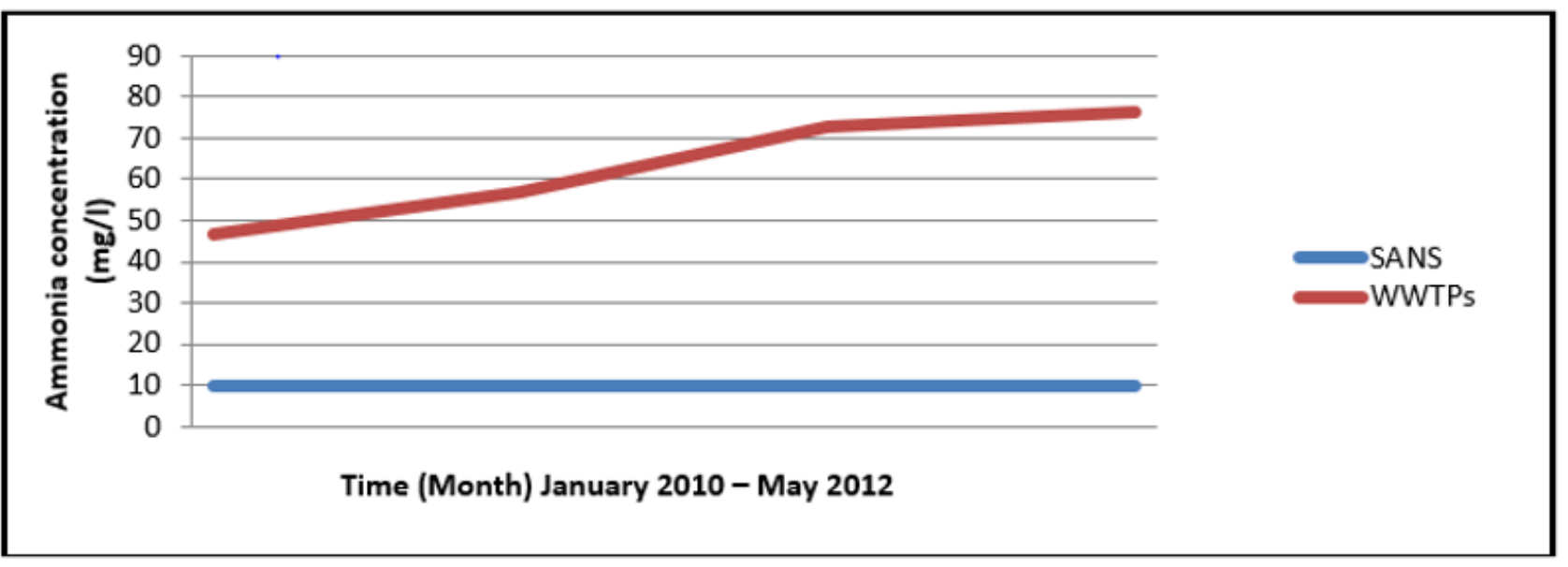

Figure 1: Concentration trend of ammonia from the current WWTPs (red) compared to the Standards (blue).

Wastewater effluents, containing a certain amount of persistent organic pollutant, are released daily from the plants and discharged into the environment. They are undeniably harmful to the entire ecosystem. "Ion exchange and reverse osmosis have failed to destroy efficiently the ammonia content from industrial wastewater effluents, due to inherent limitations" (DWA, 2012); (See Figure 1). The appearance of ammonia related to Persistent Organic Pollutants (POPs) in wastewater is likely to continue if the problem is not addressed with urgency. 2 As it can be noticed, on the picture below showing the quality of wastewater exiting the Mitchells Plain Wastewater Plants to the Indian Ocean, its quality is really a matter of concern.

Wastewater or sewage water results from household wastes, human and agricultural wastes, industrial effluents, storm run-off and ground water infiltration. Wastewater is extremely hazardous both to health and to the environment; if not well-treated, this wastewater can seriously alter the total ecosystem of the planet. Thus, the motivations for treating wastewater include the following:

a) Pollution reduction; so that the environment can be safe and clean to live in;

b) Industrial reuse of the reclaimed water;

c) Recreational and environmental uses of lakes, rivers and stream flow augmentation. This project is proposing a way of treating wastewater effluent and reducing the contamination, and thereby to make it comply with required standards prior its release back to the natural environment. Hence, the following are questioning this study will attempt to answer:

Can natural clay (Bentonite, Montmorillonite) be used as coagulant to efficiently remove ammonia in the wastewater effluents?

d) Will the addition of Nano materials such as zero valent iron nanoparticles into the mixture containing natural clay effectively play a role in the removal of POPs including ammonia from the wastewater effluent?

\section{Materials and Methodology}

\section{Materials}

a) Ash grayish bentonitic clay supplied by Kimix Chemicals \& Laboratory Suppliers located in Eppindust (South Africa), was used as the primary raw material,

b) Sulphuric acid as oxidizing agent to activate the clay to enhance its adsorptive properties [9],

c) Iron sulphate with sodium borohydride as reducing reagent, to prepare the Zero Valent Iron Nano Particles via the sulphate synthesis method or type II [10],

d) Sodium hydroxide used for mainly regulating the $\mathrm{pH}$ [11],

e) Ethanol in a specific mixture ratio with distilled water $(20: 80)$ to clean clay sample until it does not contain any SO42ions [12].

\section{Experimental}

The treatment of wastewater effluents was done at the Cape Peninsula University of Technology in the chemical engineering laboratory and the methodology will be schematically elaborated with a synoptic flow diagram process described below:

\section{Coagulant preparation}

a) Clay activation: (Figure 2)

b) Zero valent iron nanoparticles synthesis [13]

The development of the sulphate method for producing ZVINPs arose from two fundamental concerns associated with the chloride method which displays potential health-and-safety concerns associated with handling the highly acidic and very hygroscopic ferric chloride salt and deleterious effects of excessive chloride levels from the ZVINPs matrix in batch degradation tests where chlorinated hydrocarbons are the contaminant of concern. In addition, the reduction of the iron feedstock from Fe (II) requires less borohydride than the chloride method; because this method represented the second generation of iron nanoparticles, the iron is referred to as Type II ZVINPs Sulphate-method. ZVINPs were 
prepared by metering equal volumes of $0.50 \mathrm{M}$ sodium borohydride at $0.15 \mathrm{~L} / \mathrm{min}$ into $0.28 \mathrm{M}$ ferrous sulphate according to the following stoichiometry:
$2 \mathrm{Fe}_{2}+(\mathrm{aq})+\mathrm{BH}_{4}-(\mathrm{aq})+3 \mathrm{H}_{2} \mathrm{O}(\mathrm{l}) \rightarrow 2 \mathrm{Fe} 0(\mathrm{~s})+\mathrm{H}_{2} \mathrm{BO}_{3}-(\mathrm{aq})+4 \mathrm{H}+$ (aq) $+2 \mathrm{H}_{2}(\mathrm{~g})$

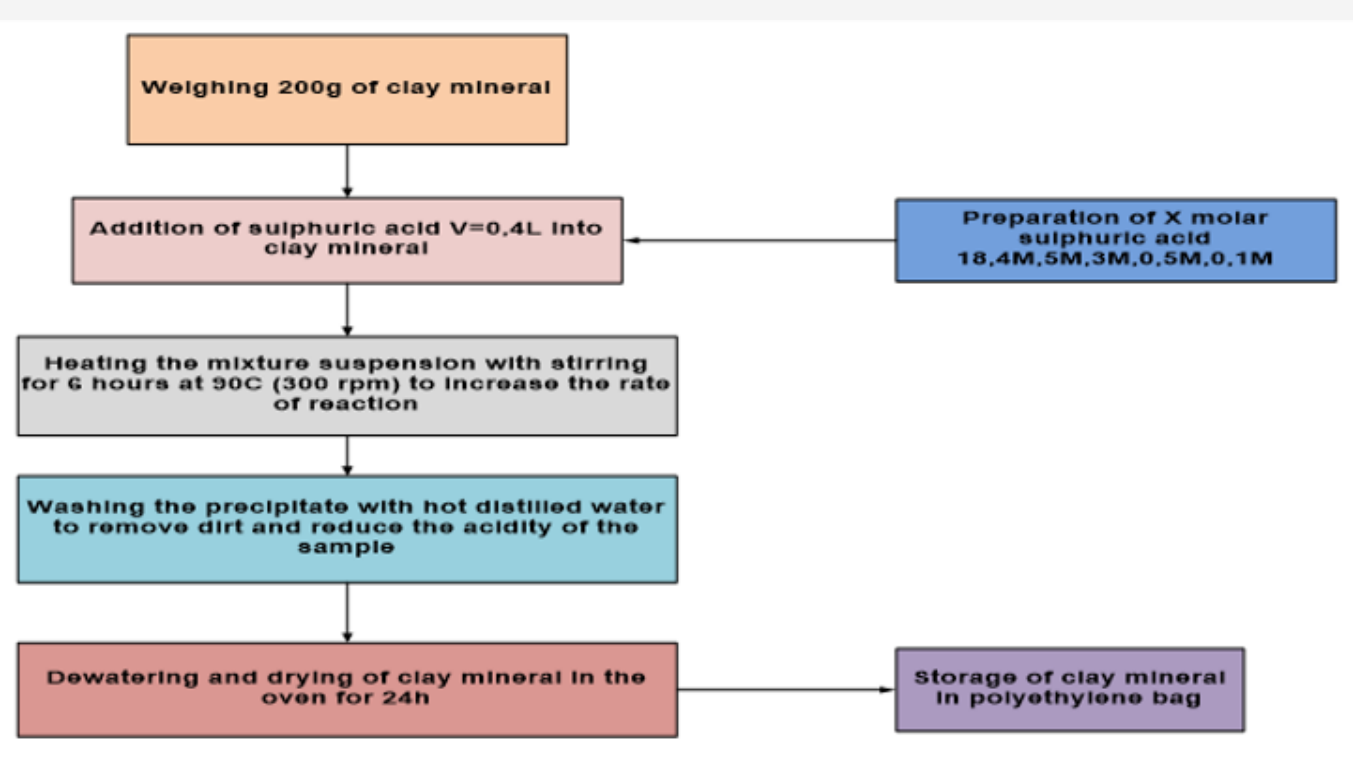

Figure 2: Standard operating procedure of clay activation.

Coagulant characterization [14,15]: The chemical and mineralogical compositions of the natural and activated clay samples were determined. The chemical composition was determined using the Transmission Electron Microscopy (FEI Tecnai F30, FEG 1K CCD, EDX, GIF, HAADF, STEM); and the mineralogical composition was studied using the X-ray diffractometer (Shimadzu XRD-6000) The specific surface area was measured at $77 \mathrm{~K}$ by BET method with a Micrometrics Gemini 2360 instrument using N2 gas.

a) Clay (Bentonite)

Relative particle size $(1-2 \mu \mathrm{m})$

Average composition: $53.2 \% \mathrm{SiO} 2,18.8 \%$

$\mathrm{Al}_{2} \mathrm{O}_{3}, 5.1 \% \mathrm{Fe}_{2} \mathrm{O}_{3}, 2.9 \% \mathrm{CaO}, 2.8 \% \mathrm{MgO}$

b) ZVINPs:

Relative particle average size (TEM): 40-50nm

Average composition (XRD): Fe0, Fe3O4, FeSO4

Surface area (BET): $40 \mathrm{~m}^{2} / \mathrm{g}$

\section{Coagulant testing conditions - Wastewater treatment [16]}

a) Water sample: $1 \mathrm{~L}$;

b) Catalyst loading: In a range of 0.00671 to $5.0505 \mathrm{~g}$ loaded into 6 different beakers of a Jar tester ( $99 \%$ Clay; 1\% ZVINPs);

c) Mixing time: $1 \mathrm{~min}$ rapid mixing at $150 \mathrm{rpm}$ and $20 \mathrm{~min}$ slow mixing at $20 \mathrm{rpm}$;

d) Settling time: $10 \mathrm{~min}$;

e) Operating pressure: $1 \mathrm{~atm}$;

f) Filtration through Membrane/normal paper filter:
Millipore nitrocellulose membrane $0.22 \mu \mathrm{m}$.

\section{Methodology flow diagram (Figure 3)}

Ammonia analysis [16]

a) Apparatus: Spectrophotometer, or Nessler tube tall form (50mL or $100 \mathrm{~mL}$ capacity), $\mathrm{pH}$ meter

b) Reagents: Zinc sulphate solution; EDTA reagent as stabilizer; Nessler's reagent; Stock ammonium solution 1.00 $\mathrm{mL}=1.00 \mathrm{mg}$.

\section{c) Procedure:}

1. Residual chlorine was removed by means of a dechlorinating agent (one or two drops sodium thiosulphate solution)

2. $100 \mathrm{~mL} \mathrm{ZnSO4}$ solution was added to $100 \mathrm{~mL}$ sample and to it was added $0.5 \mathrm{~mL}$ of $\mathrm{NaOH}$ solution to obtain a $\mathrm{pH}$ of 10.5 . This was mixed thoroughly.

3. The floc formed could settle and the clear supernatent was taken for Nesslerisation.

4. To this was added $2 \mathrm{~mL}$ of Nessler's reagent.

5. A blank using distilled ammonia free water was treated with Nessler's reagent as above. The absorbance was fixed as zero.

6. Then the sample was put in $1 \mathrm{~cm}$ standard tubes of spectrophotometer and the absorbance noted at $400-500 \mathrm{~nm}$ wavelengths.

7. A calibration curve was prepared as follows, with $0,0.2$, $0.4,0.7,1.0,1.4,1.7,2.0,2.5,3.0,4.0,5.0 \mathrm{~mL}$ of standard $\mathrm{NH} 4 \mathrm{Cl}$ 
solution in $50 \mathrm{~mL}$ distilled water standard diluted samples were prepared.

8. Each sample was Nesslerised as indicated earlier and the absorbance was noted down.
9. A graph with mg of NH3 along x-axis and absorbance along y-axis was plotted and a straight-line graph was drawn.

10. From the absorbance of a solution of unknown concentration, the $\mu \mathrm{g}$ of $\mathrm{NH} 3$ present can be read from the calibration curve.

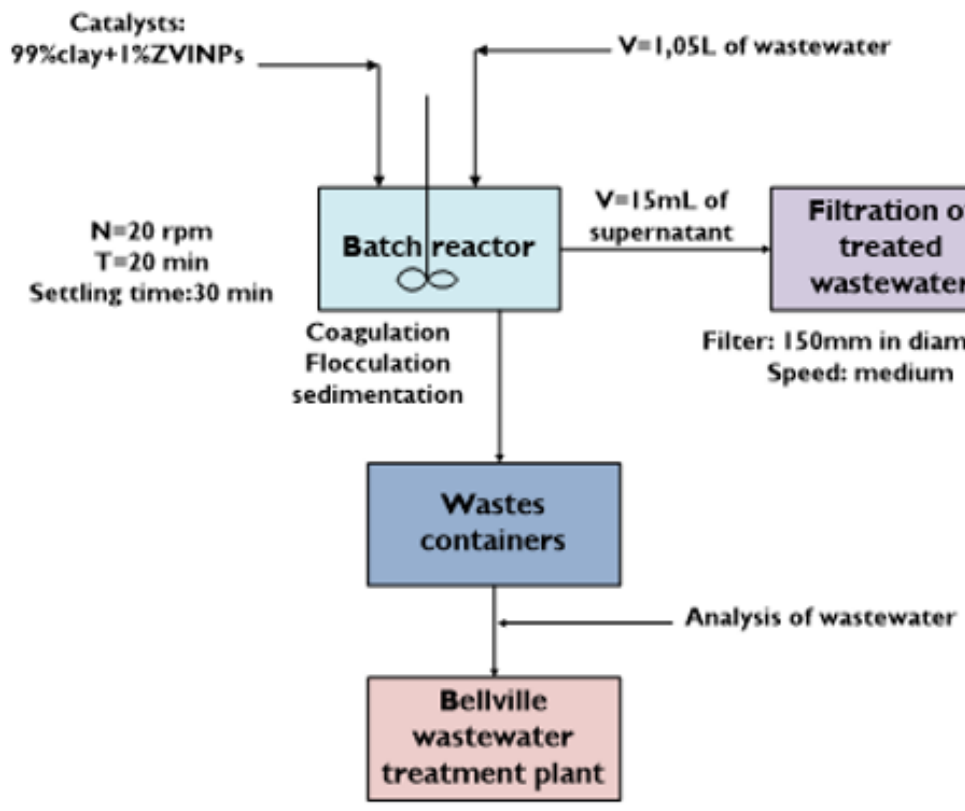

Figure 3: Block Flow Diagram of wastewater treatment.

\section{Results and Discussion}

The experiment was performed on a Jar tester apparatus and operating parameters, such as, impeller rotational speed, coagulation and resting time were constant except the $\mathrm{H} 2 \mathrm{SO} 4$ concentrations, which was varying $(0.5 \mathrm{M} ; 1 \mathrm{M} ; 3 \mathrm{M} ; 5 \mathrm{M} ; 6 \mathrm{M}$; $9 \mathrm{M}$; and $18.4 \mathrm{M}$ ). Those samples had a constant volume of $400 \mathrm{~cm} 3$ to activate $200 \mathrm{~g}$ of bentonitic clay. The table below represents the value of Clay and ZVINPs dosage used to treat $1 \mathrm{~L}$ of wastewater (Table 1\&2).
Table 1: Jar tester specification during the wastewater treatment.

\begin{tabular}{|c|c|c|}
\hline Jar Testers Number & $\begin{array}{c}\text { Weighed Mass of } \\
\text { Clay(G) }\end{array}$ & $\begin{array}{c}\text { Weighed Mass of } \\
\text { ZVINPs }(\mathrm{G})\end{array}$ \\
\hline 1 & 0.061 & 0.0061 \\
\hline 2 & 1.048 & 0.0106 \\
\hline 3 & 2.036 & 0.0206 \\
\hline 4 & 3.024 & 0.0305 \\
\hline 5 & 4.012 & 0.0405 \\
\hline 6 & 5 & 0.0505 \\
\hline
\end{tabular}

Table 2: Determination of Ammonia concentration from the beer Lambert Law.

\begin{tabular}{|c|c|c|c|c|c|c|}
\hline $\mathbf{V N H}_{4} \mathbf{C l}$ & $\mathrm{CNH}_{4} \mathbf{C l}$ & $\mathbf{V T}$ & Mwt (g/mol) & CStandard (mol/L) & C(g/L) & Absorbance \\
\hline 0.0 & 0.0712 & 50.0 & 0.0 & 0.00000 & 0.00000 & 0.0000 \\
\hline 0.2 & 0.0712 & 50.2 & 53.3 & 0.00028 & 0.00076 & 0.0002 \\
\hline 0.4 & 0.0712 & 50.4 & 53.3 & 0.00056 & 0.00151 & 0.0026 \\
\hline 0.7 & 0.0712 & 50.7 & 53.3 & 0.00098 & 0.00265 & 0.0033 \\
\hline 1 & 0.0712 & 51 & 53.3 & 0.00139 & 0.00379 & 0.0021 \\
\hline 1.4 & 0.0712 & 51.4 & 53.3 & 0.00193 & 0.00531 & 0.0021 \\
\hline 1.7 & 0.0712 & 51.7 & 53.3 & 0.00233 & 0.00645 & 0.002 \\
\hline 2 & 0.0712 & 52 & 53.3 & 0.00273 & 0.00759 & 0.0065 \\
\hline 2.5 & 0.0712 & 52.5 & 53.3 & 0.003381 & 0.00949 & 0.0009 \\
\hline 3 & 0.0712 & 53 & 53.3 & 0.004019 & 0.01139 & 0.0039 \\
\hline 4 & 0.0712 & 54 & 53.3 & 0.005259 & 0.01519 & 0.0023 \\
\hline 5 & 0.0712 & 55 & 53.3 & 0.006455 & 0.01899 & 0.007 \\
\hline
\end{tabular}

After getting the different values of the absorbance, from the methodology described previously, the calibration curve was plotted to express the amount of ammonia present in the final wastewater obtained after treatment (Figure 4). 


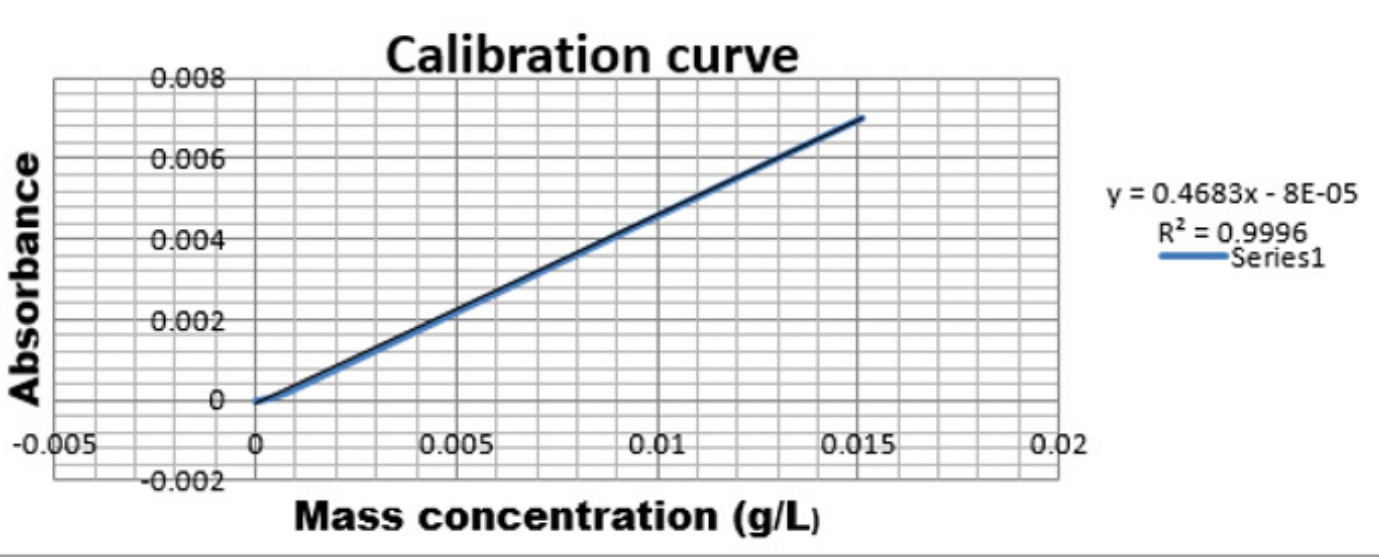

Figure 4: Determination of ammonia concentration from the calibration curve.

Previous work showed that nitrate, nitrite as well as ammonia have a similar sensitivity to $\mathrm{pH}$ with an almost 100 -fold decrease in rate constant over a pH range of 5.5 to 9.0 [17]. As pH increases beyond 8.5 , nitrate/nitrite reduction generally slows down to a greater extent [17].

The maximum reduction obtained at $5 \mathrm{M}+\mathrm{ZVINPs}$ with a neutral $\mathrm{pH}$ is defined by the maximum surface area obtained at $5 \mathrm{M}$ during acid treatment.

It was expected for ammonia to be reduced to an extent level for 18.4M+ZVINPs because of the acidic environment, and researchers proposed that reduction of nitrate/nitrite and ammonia by granular iron is favoured at low $\mathrm{pH}(2-4.5)$ [18]. Therefore the 18.4M+ZVINPs did not reduce ammonia even though the environment was acidic because of the smectite structure destruction; these results are consistent with previous studies $[19,20]$.

It can be viewed from the obtained results that the increase in catalysts dosage had no effect on the contaminants removal efficiency for most samples. It had been reported that increase in catalysts dosage increases the reduction efficiency; this means that at maximum dosage the highest contact surface between catalysts and contaminants is obtained [21]. Previous research showed that nitrite was rapidly removed in the presence of $7 \mathrm{~g} / \mathrm{L}$ of $\mathrm{Fe} 0$ over a temperature range of 25 to $50^{\circ} \mathrm{C}[19]$.

Thus, the highest amount of catalysts dosage was $5 \mathrm{~g}$ for clay and $0,0505 \mathrm{~g}$ of iron metal, the iron metal amount is low compared to previous research.

The mixing intensity was kept constant of 20rpm during treatment processes; the impeller provides proper mixing and enhances the transport of mass on granular iron surface [16].

The $5 \mathrm{M}$ bentonite+ZVINPs gave the most ammonia removal efficiency and it can be predicted that the best adsorption capacity of acid treatment was obtained at $5 \mathrm{M}$ which yield the best results of conductivity at dosages jar 1(0.0616g), jar 2(1.0586g), jar 3(2.0566g), jar 4(3.0545g), jar 5(4.0525g), jar 6(5.0505g). The significantly slower removal observed at higher $\mathrm{pH}$ values was consistent with previous research study [16].

\section{Conclusion}

The raw water had an amount of ammonia of $277 \mathrm{mg} / \mathrm{L}$, which was more than the standards set by the Department of Water Affairs and Forestry $(<10 \mathrm{mg} / \mathrm{L})$. However, the results obtained from this research showed that ammonia content was reduced for most of the sample. The best ammonia reduction was obtained at $5 \mathrm{M}+\mathrm{ZVINPs}$ for a dosage of $61.6 \mathrm{mg}$ coagulant. The ammonia was reduced from $277 \mathrm{mg} / \mathrm{L}$ to $8.71 \mathrm{mg} / \mathrm{L}$ as shown in Figure below yielding a removal efficiency of $96.85 \%$.

The coagulant used, clay, is among cheaper catalysts that can alleviate the cost of water treatment on a large scale when combined with ZVINPs (Figure 5).

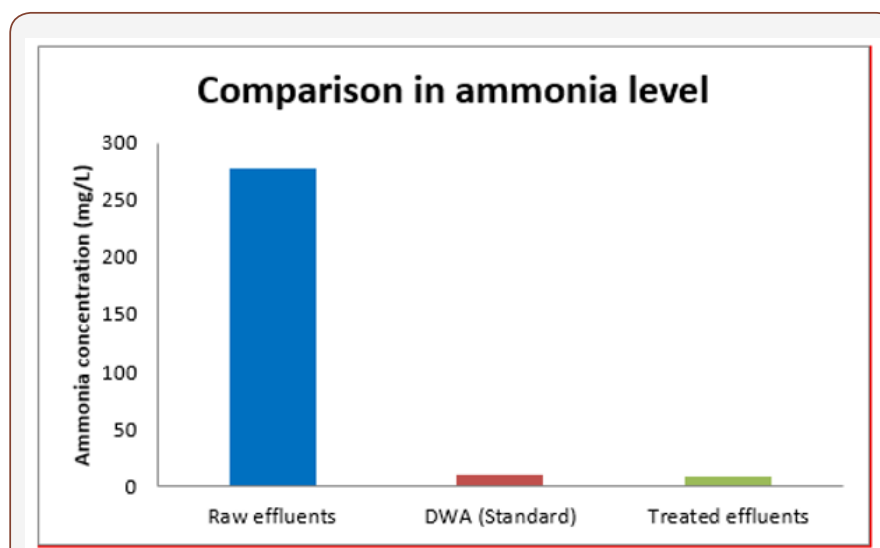

Figure 5: Comparison of Ammonia level in the wastewater (Red: South African National Standards; Blue: Raw water from the wastewater plant; Green: Treated with the hybrid coagulant).

\section{Acknowledgment}

The authors appreciate the support of the Chemical Engineering laboratory at the Cape Peninsula University of Technology (Bellville campus) in South Africa, in which almost the entire part of this work was done, and the Food Technology department of the same University where most analyses especially the Ammonia test were performed.

\section{Conflict of Interest}

No conflict of interest. 


\section{References}

1. Peters RW (1994) Alternatives for Ground Water Cleanup, Committee on Ground Water Cleanup Alternatives. National Academy Press, Washington, DC, USA, p.315.

2. Palaham W, Junyapoon S (2004) Discoloration of Reactive Blue 5 in Aqueous Solutions by Waste Iron Particle, 1st KMITL International Conference on Integration of Science and Technology for Sustainable Development, Bangkok, Thailand, 1: 217-220.

3. Department of Water Affairs (2015) The Green Handbook. Green Drop Report Index, South Africa.

4. PakWaterCare Services (2015) PWC PakWaterCare Services.

5. Schäfer P, Ritzrau W, Schlüter M, Thiede J (2001) The Northern North Atlantic: A Changing Environment.

6. Zhang WL, Wu YL, Zhao YN, Zhang X, Li HM (2007) Effects of Heat Treatment Temperature on the Photocatalytic Properties of $\mathrm{TiO}_{2}$ Prepared by Melt-Phase Separation Process. pp. 1989-1991.

7. Utracki LA (2004) Clay-Containing Polymeric Nanocomposites. Polymer News 1(1).

8. Nowack B (2010) Pollution prevention and treatment using nanotechnology, Nanotechnology: Environmental Aspects, pp. 1-15.

9. Amin S, Leila K (2009) Physicochemical variation in bentonite by sulfuric acid activation, Korean Journal of Chemical Engineering, 26(4): 980-984

10. Bors J, Dultz S, Gorny A (1998) Radiochimica Acta 74: 231-234.

11. Denysschen JH (1990) Manual on Water Purification Technology.
12. Olin NL, Peterson NT (1937) The Use of Bentonite as a Coagulant in Water Treatment. Journal (American Water Works Association 29(4): 513-522.

13. Altavilla C, Ciliberto E (2011) Inorganic Nanoparticles: Synthesis, Applications, and Perspectives. pp. 399-409.

14. Salem A, Karimi L (2009) Physicochemical variation in bentonite by sulfuric acid activation, Korean Journal of Chemical Engineering 26(4): 980-984.

15. ASTM (1995) Standard Practice for coagulation2 flocculation jar test of water, 1994, Annual book of ASTM standard, 11(02): R (1995) D 203580.

16. (1999) Standard Methods for the Examination of Water and Wastewater, American Public Health Association, American Water Works Association, Water Environment Federation.

17. Gregor JE, Nokes CJ, Fenton E (1997) Optimising Natural Organic Matter removal from low turbidity waters by controlled $\mathrm{pH}$ adjustment of aluminium coagulation. Water Research 31(12): 2949-2958.

18. Alowitz MJ, Scherer MM (2002) Kinetics of nitrate, nitrite, and Cr (VI) reduction by iron metal. Environ Sci Technol 36(3): 299-306.

19. Cloete TE, De Kwaadsteniet M, Botes M, López-Romero L (2010) Nanotechnology in Water Treatment Applications. pp 13-23.

20. Cloete TE, De Kwaadsteniet M, Botes M, López-Romero L (2010) Nanotechnology in Water Treatment Applications. pp. 15-22.

21. Pan JR, Huang C, Chen S, Chung YC (1999) Evaluation of a modified chitosan biopolymer for coagulation of colloidal particles. Physiochemical and Engineering Aspects 147(3): 359-364. 